\title{
EVALUASI KINERJA PENYULUH PERTANIAN LAPANGAN (PPL) DI KECAMATAN PELEPAT ILIR KABUPATEN BUNGO
}

\author{
EVALUATION OF PERFORMANCE OF FIELD AGRICULTURAL EXTENSION \\ IN PELEPAT ILIR DISTRICT OF BUNGO REGENCY
}

\author{
Margono and Evo Afrianto \\ Agriculture Faculty Agribusiness Study Program \\ Muara Bungo University \\ evo_juventini@yahoo.com
}

\begin{abstract}
ABSTRAK
Penelitian ini dilakukan Untuk mengetahui tingkat kinerja Penyuluh Pertanian Lapangan (PPL), dan Untuk menganalisis hubungan Kemampuan Teknis, Kemampuan Konseptual dan Kemampuan interpersonal terhadap kinerja Penyuluh Pertanian Lapangan (PPL) di Kecamatan Pelepat Ilir Kabupaten Bungo.

Metode penelitian dalam penelitian ini untuk menganalisis kinerja Penyuluh Pertanian Lapangan (PPL) di Kecamatan Pelepat Ilir Kabupaten Bungo dilakukan dengan analisis deskriptif melalui scoring dan tabel kontingensi. Selanjutnya untuk mengetahui hubungan Kemampuan Teknis, Kemampuan Konseptual dan Kemampuan interpersonal terhadap kinerja Penyuluh Pertanian Lapangan (PPL) di Kecamatan Pelepat Ilir Kabupaten Bungo, maka dianalisis secara statistik non parametrik dengan mengunakan Uji Koefisien Rank Spearman.

Berdasarkan hasil dan pembahasan maka dapat diambil kesimpulan bahwa kemampuan teknis, kemampuan konseptual dan kemampuan interpersonal penyuluh pertanian lapangan di Kecamatan Pelepat Ilir Kabupaten Bungo dalam melaksankan tugasnya sebagai penyuluhan pertanian lapangan dikategori tinggi. Dan begitu juga kinerja Penyuluh Pertanian Lapangan (PPL) di Kecamatan Pelepat Ilir Kabupaten Bungo dikategori tinggi. Selanjutnya kemampuan teknis dan kemampuan konseptual terdapat hubungan yang nyata terhadap Kinerja Penyuluhan Pertanian Lapangan (PPL) di Kecamatan Pelepat Ilir Kabupaten Bungo.Sedangkan kemampuan interpersonal tidak terdapat hubungan yang nyata terhadap Kinerja Penyuluhan Pertanian Lapangan (PPL) di Kecamatan Pelepat Ilir Kabupaten Bungo
\end{abstract}

Kata Kunci : Evaluasi Kinerja. Penyuluh Pertanian Lapangan (PPL)

\begin{abstract}
This research was conducted to determine the performance level of Field Agricultural Extension and To analyze the relationship of Technical Ability, Conceptual Ability and Interpersonal Ability to the performance of Field Agricultural Extension in the District of Pelepat Ilir, Bungo Regency
\end{abstract}


The research method in this study to analyze the performance of Field Agricultural Extension in Pelepat Ilir District, Bungo Regency was carried out by descriptive analysis through scoring and contingency tables. Furthermore, to find out the relationship between Technical Ability, Conceptual Ability and Interpersonal Ability to the performance of Field Agricultural Extension Workers in Pelepat Ilir District, Bungo Regency, it was analyzed statistically non parametric by using the Spearman Rank Coefficient Test.

Based on the results and discussion, it can be concluded that the technical capabilities, conceptual abilities and interpersonal skills of the field agricultural instructors in Pelepat Ilir District, Bungo Regency in carrying out their duties as agricultural field counseling in the high category. And so is the performance of Field Agricultural Extension in Pelepat Ilir District, Bungo Regency in the high category. Furthermore, the technical capabilities and conceptual abilities have a significant relationship to the Field Agricultural Extension Performance in the District of Pelepat Ilir, Bungo Regency. Whereas interpersonal skills do not have a real relationship to Field Agricultural Extension Performance in the District of Pelepat Ilir, Bungo Regency.

\section{Keywords: Performance Evaluation. Field Agricultural Extension}

\section{PENDAHULUAN}

\section{Latar Belakang}

Penyuluh pertanian di Indonesia telah memberi kontribusinya pada pencapaian program dalam pembangunan pertanian. Kegiatan penyuluhan dalam pembangunan pertanian berperan sebagai jembatan yang menghubungkan antara praktek yang dijalankan oleh petani dengan pengetahuan dan teknologi petani yang selalu berkembang menjadi kebutuhan para petani tersebut (Kartasapoetra, 1994). Agar petani dapat melakukan praktek yang mendukung usahatani maka petani membutuhkan informasi inovasi dibidang pertanian, informasi tersebut dapat diperoleh petani dari penyuluh pertanian lapangan melalui penyelenggaraan kegiatan penyuluhan pertanian. Kegiatan penyuluhan pertanian dilakukan untuk membantu mengatasi berbagai permasalahan yang dihadapi para petani (Gitosaputro, dkk, 2012). Menurut Mosher (1981), untuk meningkatkan kontribusi sektor pertanian,

peran penyuluh pertanian adalah penting, oleh karena itu kualitas sumberdaya manusia terutama penyuluh sangat berpengaruh dalam pembangunan pertanian. Menurut Kartasapoetra (1994), penyuluh pertanian diarahkan untuk melaksanakan tugas pendampingan dan konsultasi bagi pelaku utama dan pelaku usaha dalam mengembangkan usaha agribisnisnya, sehingga adopsi teknologi tepat guna dapat berjalan dengan baik dan pada gilirannya meningkatkan pemberdayaan pelaku utama, produksi, produktivitas, pendapatan dan kesejahteraan petani beserta keluarganya.

Provinsi Jambi sektor pertanian merupakan salah satu yang memberi kontribusi dalam perekonomian wilayah, itu tidak 
terlepas dari dari penyuluhan pertanian, untuk itulah dibutuhkan sistem penyuluhan yang handal sebagaimana yang diamanatkan didalam Undang - undang 16 tahun 2006 tentang Sistem Penyuluh Pertanian, Perikanan dan Kehutanan (SP3K), sedangkan mengenai tugas pokok penyuluh pertanian diatur dalam Pereturan Mentri Pertanian No : $\quad 61 /$ Permentan/OT.140/11/2008 yaitu tugas pokok penyuluhan pertanian swadaya dan penyuluhan pertanian swasta adalah melakukan kegiatan penyuluhan pertanian kepada pelaku utama dan pelaku usaha sesuai dengan rencana kerja penyuhan pertanian yang disusun berdasrkan programa penyuluhan pertanian diwilayah kerja.

Kabupaten Bungo merupakan salah satu kebupaten yang telah melaksanakan berbagai program pembangunan pertanian dalam upaya meningkatkan taraf hidup masyarakat, mengurangi angka kemiskinan, menurunkan angka pengangguran melalui perencanaan pertanian terpadu dalam penyuluhan pertanian. Balai Penyuluhan Pertanian (BPP) Kecamatan Pelepat Ilir merupakan salah satu BPP yang berada di Kabupaten Bungo yang memiliki peran sebagai tempat perencanaan, pelaksanaan, monitoring dan pengevaluasian program - program penyuluhan pertanian yang telah dilaksanakan oleh penyuluh pertanian, pembinaan yang dilakukan BPP dilakukan secara terprogram dan berkesinambungan sehingga akan mampu menghimpun, mengerakkan, membimbing dan mengarahkan petani dalam melaksanakan usahataninya.

Balai Penyuluhan Pertanian

(BPP) Kecamatan Pelepat Ilir
Kabupaten Bungo yang menjadi prioritas petni yaitu tanaman hortikultura dan buah - buahan seperti cabe, semangka, melon, sayur-sayuran lainnya dan jagung. Hal ini disebabkan kondisi tanah maupun iklim yang mendukung untuk komoditi tersebut, petani juga mendukung program pemerintah yaitu swasembada pangan. Untuk itu penyuluh pertanian dituntut untuk lebih meningkatkan kinerjanya, maka perlu diketahui secara jelas kinerja penyuluh pertanian.

Hal ini berkaitan dengan kinerja dan tanggung jawab seorang penyuluh. Kinerja ialah hasil kerja secara kualitas dan kuantitas yang dicapai oleh seorang pegawai dalam melaksanakan tugasnya sesuai dengan tanggung jawab yang diberikan kepadanya (Mangkunegara, 2000). Penilaian kinerja mengacu pada suatu sistem formal dan terstruktur yang digunakan untuk mengukur, menilai dan mengamati sifat - sifat yang berkaitan dengan pekerjaan, perilaku dan hasil termasuk kehadiran. Dalam menilai kinerja dibutuhkan proses evaluasi sebagai indikator keberasilan dalam melaksanakan tugasnya. Menurut Harrby dan Parwell (1987) dalam Mardikanto (1996) evaluasi aalah suatu tindakan pengambilan keputusan untuk menilai suatu objek, keadaan, peristiwa atau kegiatan tertentu yang diamati sehingga pada akhirnya digunakan sebagai pergantian atau persamaan karena pada dasarnya mempunyai maksud yang sama.

$$
\text { Lemahnya }
$$

ataupun berhasilnya kinerja penyuluhan pertanian tidak terlepas dari evaluasi. Evaluasi penyuluhan pertanian dapat digunakan untuk memperbaiki perencanaan kegiatan / program 
penyuluhan, kinerja penyuluhan, mempertanggung jawabkan kegiatan yang dilaksanakan, membandingkan antara kegiatan yang dicapai dengan tujuan yang telah ditetapakan.

Adapun tujuan dari penelitian ini adalah Untuk mengetahui tingkat kinerja Penyuluh Pertanian Lapangan (PPL) dan untuk menganalisis hubungan Kemampuan Teknis, Kemampuan Konseptual dan Kemampuan interpersonal terhadap kinerja Penyuluh Pertanian Lapangan (PPL) di Kecamatan Pelepat Ilir Kabupaten Bungo

Berdasarkan uruaian diatas maka penulis tertarik untuk melaukan penelitian dengan judul

"Evaluasi Kinerja Penyuluh Pertanian Lapangan (PPL) Di Kecamatan Pelepat Ilir Kabupaten Bungo".

\section{METODOLOGI PENELITIAN}

Metode penelitian yang digunakan adalah metode deskriptif

$$
r_{s}=1-\frac{6 \sum d^{2}}{n^{3}-n}
$$

yaitu metode penelitian yang berusaha menuturkan pemecahan masalah yang ada sekarang berdasarkan data, sehingga penelitian ini juga menyajikan data, menganalisis, dan menginterpretasi (Achmadi dan Narbuko, 2003).

Untuk menyederhanakan data yang telah diperoleh, maka dilakukan tabulasi, kemudian untuk menganalisis kinerja Penyuluh Pertanian Lapangan (PPL) di Kecamatan Pelepat Ilir Kabupaten Bungo dilakukan dengan analisis deskriptif melalui scoring dan tabel kontingensi. Selanjutnya untuk mengetahui hubungan Kemampuan Teknis, Kemampuan Konseptual dan Kemampuan interpersonal terhadap kinerja Penyuluh Pertanian Lapangan (PPL) di Kecamatan Pelepat Ilir Kabupaten Bungo, maka dianalisis secara statistik non parametrik dengan mengunakan Uji Koefisien Rank Spearman, dengan rumus sebagai berikut: (Silalahi. 2012)

Dimana :

$$
\begin{aligned}
& \mathrm{rs}=\text { Koofisien Korelasi Spearman } \\
& \mathrm{di}^{2}=\text { Perbedaan setiap pasangan ranking } \\
& \mathrm{N}=\text { Jumlah Sampel }
\end{aligned}
$$

Hipotesis yang akan dibuktikan kebenarannya dalam penelitian ini dapat dirumuskan sebagai berikut :

Ho : rs $=0$

$\mathrm{Hi}: \mathrm{rs} \neq 0$

Digunakan Uji t, karena n (ukuran sampel) > 10. Adapun rumus yang digunakan :

$$
\mathrm{t}=\mathrm{r}_{\mathrm{s}} \sqrt{\frac{N-2}{1-r s^{2}}}
$$

Adapun kaidah pengambilan keputusannya adalah :

Ho diterima apabila rs hitung < rs tabel $(0,05)$

Hi diterima apabila rs hitung $>$ rs tabel $(0,05)$

\section{HASIL DAN PEMBAHASAN}


Kemampuan Penyuluh Pertanian Lapangan (PPL)

\section{Kemampuan Teknis}

Kemampuan teknis penyuluh pertanian lapangan merupakan salah satu indikator yang digunakan dalam penelitian ini. Menurut Rivai (2003) kemampuan teknis adalah kemampuan untuk menggunakan pengetahuan, metode, teknik dan peralatan yang digunakan untuk melaksanakan tugas pengalaman serta pelatihan yang diperlukan. Untuk distribusi frekuensi kemampuan teknis dapat dilihat pada Tabel 1.

Tabel 1. Distribusi Frekuensi Sampel Berdasarkan Kemampuan Teknis Di Daerah Penelitian Tahun 2018.

\begin{tabular}{ccc}
\hline Kemampuan Teknis & $\begin{array}{c}\text { Frekuensi } \\
\text { (orang) }\end{array}$ & Persentase (\%) \\
\hline Tinggi & 5 & 83,33 \\
Rendah & 1 & 16,67 \\
\hline Jumlah & 6 & $100 \%$ \\
\hline
\end{tabular}

Sumber : hasil olahan primer tahun 2018

Tabel 1 dapat diketahui bahwa sampel didaerah penelitian mempunyai kemampuan teknis yang kategori tinggi yaitu 5 orang $(83,33$ $\%)$. Tingginya kemampuan teknis responden disebabkan oleh pengetahuan teknik budidaya dan cara pemeliharaan tanaman, cara pemilihan bibit unggul serta tata cara pemupukan pada tanaman dan juga frekuensi penyuluhan yang cukup baik.

\section{Kemampuan Konseptual}

\begin{abstract}
Kemampuan konseptual adalah kemampuan penyuluhan pertanian lapangan untuk memahami tugas - tugas serta tanggung jawabnya sebagai penyuluh. Parameter yang digunakan dalam penelitian ini yaitu kemampuan menguasai jenis media penyuluhan dan pencapaian target produksi tanaman setelah dilakukan penyuluhan. Untuk melihat kemampuan konseptual penyuluh pertanian lapangan dapat dilihat pada tabel 2 berikut.
\end{abstract}

Tabel 2. Distribusi Frekuensi Sampel Berdasarkan Kemampuan Konseptual Di Daerah Penelitian Tahun 2018.

\begin{tabular}{rcc}
\hline $\begin{array}{c}\text { Kemampuan } \\
\text { Konseptual }\end{array}$ & $\begin{array}{c}\text { Frekuensi } \\
\text { (orang) }\end{array}$ & Persentase (\%) \\
\hline Tinggi & 4 & 66,67 \\
Rendah & 2 & 33,33 \\
\hline
\end{tabular}




\begin{tabular}{ccc}
\hline Jumlah & 6 & $100 \%$ \\
\hline
\end{tabular}

\section{Sumber : hasil olahan primer tahun 2018.}

Dari Tabel 2 dapat diketahui bahwa responden didaerah penelitian

memiliki kemampuan konseptual yang tinggi yaitu sebanyak 4 orang $(66,67 \%)$. Tingginya kemampuan konseptul dikarenakan responden sudah menguasai media penyuluhan sebelum turun ke lapanagan untuk melaksanakan kegiatan penyuluhan kepada petani, sehingga pada saat memberi penyuluhan lebih mudah dipahami oleh petani dan dampaknya pada hasil tanaman petani yang produksinya cukup baik.

\section{Kemampuan Interpersonal}

Kemampuan interpersonal
penyuluh pertanian lapangan
merupakan kemampuan penyuluh
untuk bekerjasama dengan penyuluh
lain, memotivasi serta berkonsultasi
dengan atasan. Untuk lebih jelasnya
dapat dilihat pada tabel 3 berikut.

Tabel 3. Distribusi Frekuensi Sampel Berdasarkan Kemampuan Interpersonal Di Daerah Penelitian Tahun 2018.

\begin{tabular}{ccc}
\hline $\begin{array}{c}\text { Kemampuan } \\
\text { Interpersonal }\end{array}$ & $\begin{array}{c}\text { Frekuensi } \\
\text { (orang) }\end{array}$ & Persentase (\%) \\
\hline Tinggi & 4 & 66,67 \\
Rendah & 2 & 33,33 \\
\hline Jumlah & 5 & $100 \%$ \\
\hline
\end{tabular}

Sumber : hasil olahan primer tahun 2018.

Dari Tabel 3 menunjukkan bahwa kemampuan interpersonal didaerah penelitian berada pada kategori tinggi yaitu 4 orang $(55,67 \%)$. Tingginya kemampuan interpersonal yang diperoleh disebabkan mampunya responden memotivasi petani dalam meningkatkan usahataninya, selain itu juga melakukan kerjasama sehingga mempunyai kinerja yang cukup tinggi dalam pelaksanaan tugas sebagai penyuluhan pertaniaan lapangan.

\section{Kinerja Penyuluhan Pertanian Lapangan (PPL)}

Kinerja merupakan hasil kerja secara kualitas dan kuantitas yang dicapai oleh seorang pegawai dalam melaksanakan tugasnya sesuai dengan tanggung jawab yang diberikan kepadanya. Menurut Mangkunegara (2005) menyataan kinerja seorang penyuluh pertanian dapat dilihat dari mutu penyuluhan yang diberikan pada petani. Untuk lebih jelasnya dapat dilihat pada tabel 8 berikut. 
Tabel 4. Distribusi Frekuensi Sampel Berdasarkan Kenerja Penyuluh Pertanian Lapangan Di Daerah Penelitian Tahun 2018.

\begin{tabular}{ccc}
\hline $\begin{array}{c}\text { Kemampuan } \\
\text { Merencanakan } \\
\text { Kegiatan }\end{array}$ & $\begin{array}{c}\text { Frekuensi } \\
\text { (orang) }\end{array}$ & Persentase (\%) \\
\hline Tinggi & 6 & 100 \\
Rendah & 0 & 0 \\
\hline Jumlah & 6 & $100 \%$
\end{tabular}

Sumber : hasil olahan primer tahun 2018.

Tabel 4 menenjukan bahwa kinerja dalam melaksanakan tugas penyuluhan pertanian lapangan didaerah penelitian dikategori tinggi sebanyak 6 orang $(57,58 \%)$, ini artinya responden didaerah penelitian memiliki kinerja yang baik.

\section{Hubungan Kemampuan Terhadap Kinerja Penyuluhan Pertanian Lapangan (PPL)}

1. Hubungan Kemampuan Teknis Terhadap Kinerja Penyuluhan Pertanian Lapangan (PPL)

Berdasarkan hasil penelitian yang dilakukan mengenai hubungan kemampuan teknis terhadap Kinerja Penyuluhan Pertanian Lapangan (PPL) untuk lebih jelasnya dapat dilihat pada Tabel 5 berikut ini.

Tabel 5. Hubungan Kemampuan Teknis Terhadap Kinerja Penyuluhan Pertanian Lapangan (PPL) Di Daerah Penelitian Tahun 2018.

\begin{tabular}{cccc} 
Kemampuan & \multicolumn{3}{c}{ Kinerja Penyuluhan Pertanian Lapangan } \\
Teknis & Tinggi & Rendah & Jumlah \\
\cline { 2 - 4 } & 5 & 0 & 5 \\
Tinggi & 1 & 0 & 1 \\
Rendah & 6 & 0 & 6 \\
\hline Jumlah & 6 &
\end{tabular}

Sumber : hasil olahan primer tahun 2018.

Tabel 5 memperlihatkan bahwa hubungan kemampuan teknis terhadap Kinerja Penyuluhan Pertanian Lapangan (PPL) tergolong tinggi, yaitu 5 orang dengan kategori tinggi dan 1 orang dengan kategori rendah. Dengan demikian dapat dikatakan bahwa semakin tinggi 
kemampuan teknis semakin tinggi pula kinerja PPL begitu juga sebaliknya semakin rendah kemampuan teknis semakin rendah pula kinerja PPL.

Berdasarkan uraian diatas, hubungan dan dianalisis menggunakan statistik non parametrik dengan uji hasil Rank Spearman. Melalui statistik non parametrik uji hasil Rank Spearman didapat sebesar 0,91, besarnya derajat kemampuan teknis terhadap Kinerja Penyuluhan Pertanian Lapangan (PPL) adalah sebesar 91\%. Sedangkan nilai $t_{\text {hit }} 4,41>t_{\text {tabel }}$ 0,0105 , sehingga diambil suatu keputusan bahwa tolak Ho. Dimana hal tersebut menggambarkan bahwa terdapat hubungan yang nyata kemampuan teknis terhadap Kinerja Penyuluhan Pertanian Lapangan (PPL) di Kecamatan Pelepat Ilir Kabupaten Bungo.

\section{Hubungan Kemampuan Konseptual Terhadap Kinerja Penyuluhan Pertanian Lapangan (PPL)}

Berdasarkan hasil penelitian yang dilakukan mengenai hubungan kemampuan konseptual terhadap Kinerja Penyuluhan Pertanian Lapangan (PPL) untuk lebih jelasnya dapat dilihat pada Tabel 6 berikut ini.

Tabel 6. Hubungan Kemampuan Konseptual Terhadap Kinerja Penyuluhan Pertanian Lapangan (PPL) Di Daerah Penelitian Tahun 2018.

\begin{tabular}{|c|c|c|c|}
\hline \multirow{2}{*}{$\begin{array}{l}\text { Kemampuan } \\
\text { Konseptual }\end{array}$} & \multicolumn{3}{|c|}{$\begin{array}{c}\text { Kinerja Penyuluhan Pertanian Lapangan } \\
\text { (PPL) }\end{array}$} \\
\hline & Tinggi & Rendah & Jumlah \\
\hline Tinggi & 4 & 0 & 4 \\
\hline Rendah & 2 & 0 & 2 \\
\hline Jumlah & 6 & 0 & 6 \\
\hline
\end{tabular}

Sumber : hasil olahan primer tahun 2018.

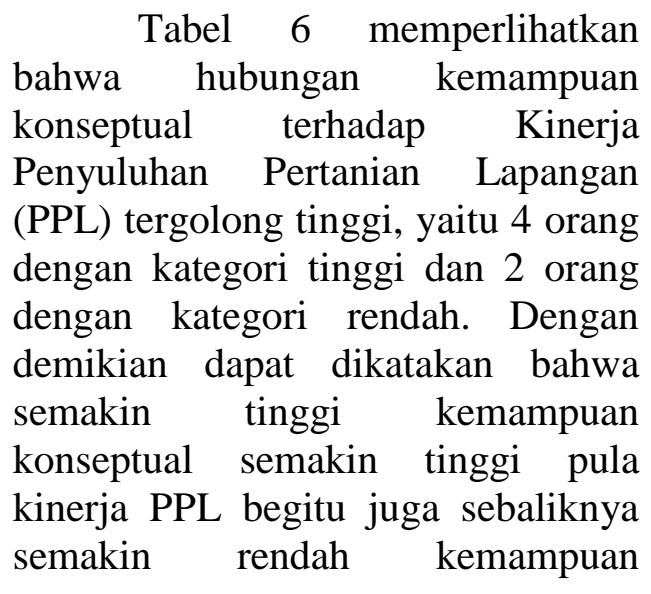

konseptual semakin rendah pula kinerja PPL.

Berdasarkan uraian diatas, hubungan dan dianalisis menggunakan statistik non parametrik dengan uji hasil Rank Spearman. Melalui statistik non parametrik uji hasil Rank Spearman didapat sebesar 0,61, besarnya derajat kemampuan konseptual terhadap Kinerja Penyuluhan Pertanian Lapangan (PPL) adalah 
sebesar $61 \%$. Sedangkan nilai $t_{\text {hit }}$ $1,54>t_{\text {tabel }} 0,0105$, sehingga diambil suatu keputusan bahwa tolak Ho. Dimana hal tersebut menggambarkan bahwa terdapat hubungan yang nyata kemampuan konseptual terhadap Kinerja Penyuluhan Pertanian Lapangan (PPL) di Kecamatan Pelepat Ilir Kabupaten Bungo.
3. Hubungan Kemampuan

Interpersonal Terhadap

Kinerja Penyuluhan Pertanian Lapangan (PPL)

Berdasarkan hasil penelitian yang dilakukan mengenai hubungan kemampuan interpersonal terhadap Kinerja Penyuluhan Pertanian Lapangan (PPL) untuk lebih jelasnya dapat dilihat pada Tabel 7 berikut ini.

Tabel 7. Hubungan Kemampuan Interpersonal Terhadap Kinerja Penyuluhan Pertanian Lapangan (PPL) Di Daerah Penelitian Tahun 2018.

\begin{tabular}{rccc}
\hline & \multicolumn{3}{c}{ Kinerja Penyuluhan Pertanian Lapangan } \\
Kemampuan & & (PPL) & \\
\cline { 2 - 4 } & Tinterpersonal & Rendah & Jumlah \\
\cline { 2 - 4 } Tinggi & 4 & 0 & 4 \\
Rendah & 2 & 0 & 2 \\
\hline Jumlah & 6 & 0 & 6 \\
\hline
\end{tabular}

Sumber : hasil olahan primer tahun 2018.

Tabel 7 memperlihatkan bahwa hubungan kemampuan interpersonal terhadap Kinerja Penyuluhan Pertanian Lapangan (PPL) tergolong tinggi, yaitu 4 orang dengan kategori tinggi dan 4 orang dengan kategori rendah. Dengan demikian dapat dikatakan bahwa semakin tinggi kemampuan interpersonal semakin tinggi pula kinerja PPL begitu juga sebaliknya semakin rendah kemampuan interpersonal semakin rendah pula kinerja PPL.

Berdasarkan uraian diatas, hubungan dan dianalisis menggunakan statistik non parametrik dengan uji hasil Rank Spearman. Melalui statistik non parametrik uji hasil Rank Spearman didapat sebesar 0,00 , besarnya derajat kemampuan interpersonal terhadap Kinerja Penyuluhan Pertanian Lapangan (PPL) adalah sebesar $0 \%$. Sedangkan nilai $t_{\text {hit }}$ $0,00<t_{\text {tabel }} 0,0105$, sehingga diambil suatu keputusan bahwa terima Ho. Dimana hal tersebut menggambarkan bahwa tidak terdapat hubungan yang nyata kemampuan interpersonal terhadap Kinerja Penyuluhan Pertanian Lapangan (PPL) di Kecamatan Pelepat Ilir Kabupaten Bungo.

\section{KESIMPULAN DAN SARAN}

Kesimpulan 
Berdasarkan penelitian dan pembahasan dapat ditarik kesimpulan antara lain:

1. Berdasarkan hasil dan pembahasan maka dapat diambil kesimpulan bahwa kemampuan teknis, kemampuan konseptual dan kemampuan interpersonal penyuluh pertanian lapangan di Kecamatan Pelepat Ilir Kabupaten Bungo dalam melaksankan tugasnya sebagai penyuluhan pertanian lapangan dikategori tinggi. Dan begitu juga kinerja Penyuluh Pertanian Lapangan (PPL) di Kecamatan Pelepat Ilir Kabupaten Bungo dikategori tinggi.

2. Kemampuan teknis dan kemampuan konseptual terdapat hubungan yang nyata terhadap Kinerja Penyuluhan Pertanian Lapangan (PPL) di Kecamatan Pelepat Ilir Kabupaten Bungo.Sedangkan kemampuan interpersonal tidak terdapat hubungan yang nyata terhadap Kinerja Penyuluhan Pertanian Lapangan (PPL) di Kecamatan Pelepat Ilir Kabupaten Bungo.

\section{Saran}

1. Untuk penyuluh pertanian lapangan (PPL) di Kecamatan Pelepat Ilir Kabupaten Bungo tetap pertahankan terus kinerjanya bahkan kalau perlu ditingkatkan lagi.

2. Kepada pemerintah untuk memperhatikan kondisi kerja yang kondusif dan mampu memenuhi harapan, kebutuhan dan keinginan penyuluh pertanian lapangan (PPL).

\section{DAFTAR PUSTAKA}

Adjid, DA. 2001. Penyuluh Pertanian. Yayasan Sinar Tani. Jakarta.

Gitosaputro, S., Listiana I., Gultom DT. 2012. Dasar-dasar Penyuluhan dan Komunikasi Pertanian. Anugrah Utama Raharja. Bandar Lampung.

Hasugian. 2013. Evaluasi Kinerja Balai Penyuluhan Pertania (BPP) Kabupaten Pakpak Bharat. Jurnal Universitas Sumatera Utara. Medan

Kartasapoetra, AG. 1994. Teknologi Penyuluhan Pertanian. Bina Aksara. Jakarta.

Lubis, RA. 2014. Faktor-faktor yang Mempengaruhi Kinerja Penyuluh Pertanian di Kabupaten Mandailing Natal. Tesis. Universtas Sumatera Utara. Medan

Mangkunegara AP. 2000. Evaluasi Kinerja Sumber Daya Manusia. PT Refika Aditama. Bandung.

Mardikanto, T. 1996. Penyuluhan Pembangunan Pertanian. Universitas Sebelas Maret Press. Surakarta.

Mosher, AT. 1981. Menggerakkan dan Membangun Pertanian. CV. Yasa Guna. Jakarta.

Nabila. I. 2013. Pengaruh Lingkungan Kerja, Kemampuan Kerja dan Kompensasi terhadap Kinerja Karyawan Bagian Produksi PJ. Muria Jaya Kudus. Diponegoro Journal Of Social and Politic. 
Nurul. 2014. Evaluasi Peran Pendamping Terhadap Keberhasilan Program Desa Mandiri Pangan Di Kabupaten Bantul. Skripsi. Universitas Gadjah Mada. Yogyakarta

Ralph. W. Tyler. 1989. Education Evaluation: Classic Work. Boston, MA: Kluwer Academic Publishers.

Ridwuan. 2009. Rumus dan Data dalam Aplikasi Statistika untuk Penelitian. Alfabeta, Bandung.

Sastraatmadja, E. 1986. Penyuluh Pertanian. Alumni. Bandung.

Seigel, Siedney. 1997. Statistik Nonparametik untuk Ilmuilmu Sosial. Jakarta

Silalahi. U. 2012. Metode Penelitian Sosial. PT. Refika Aditama. Bandung
Singarimbun, $M$ dan S. Effendi. 1995. Metode Penelitian Survey. LP3ES. Jakarta

Soekartawi. 1995. Dasar Penyusunan Evaluasi Proyek. Pustak Sinar Harapan. Jakarta

Suhardiyono, L. 1988. Penyuluh: Petunjuk Bagi Penyuluh Pertanian. Erlangga. Jakarta

Suharsimi Arikunto. 2004. Dasar dasar Evaluasi Pendidikan. Bumi Aksara. Jakarta

Sulistiyani. 2003. Management Sumber Daya Manusia. Graha Ilmu. Jakarta.

Umar, Burham. 2002. Studi Kelayakan dan Evaluasi Proyek. Bumi Aksara. Jakarta

Van den Ban, AW dan Hawkins, HS 1999. Penyuluhan

Pertanian.

Kanisus. Yogyakarta. 